\title{
Severe pain and weakness in lower extremities in a lung adenocarcinoma case
}

\author{
M Zahid Kocak, Gulali Aktas*, Edip Erkus, Tuba Duman, Burcin Atak and Haluk Savli \\ Abant Izzet Baysal University Hospital, Department of Internal Medicine, Bolu, Turkey
}

\begin{abstract}
Neuropathy may complicate the course of the disease in subjects with cancer. Here we report a middle aged man with lung cancer whom presented to our clinic with weakness in lower extremities. A 49 years old man presented with pain and weakness in the legs and pretibial edema. His complaints were began 2 months ago. He reported that he was a heavy smoker by smoking 2 to 3 packets of cigarettes daily, for 30 years. Thoracic CT revealed a mass with in apical of basal segment of lower lobe in right lung and a metastatic mass lesion, destructed the $3^{\text {rd }}$ right costa laterally. CT was also revealed widespread metastatic nodules in the liver. Lytic metastatic lesions were noted in T1,T5-8 and L1 vertebrae. Biopsy of the mass has been reported as adenocarcinoma of the lung. Weakness and pain in extremities in a subject with a history of heavy smoking should alert physicians for possible lung malignancy. A thoracic CT should be performed for establishing diagnosis.
\end{abstract}

\section{Introduction}

Cancer patients may suffer from neuropathy via different ways. It may be associated with tumoral infiltration of the spinal cord, chemotherapy, metabolic complications such as hypercalcemia, nutritional deficits or paraneoplastic syndrome. Neuropathy eventually develops in about $15 \%$ of the cancer cases [1].

Here we report a middle-aged man with lung cancer whom presented to our clinic with weakness in lower extremities.

\section{Case Report}

A 49 years old man presented with pain and weakness in the legs and pretibial edema. His complaints were began 2 months ago. Leg pain was getting more severe day by day. Despite he was not complaining of numbness, weakness was worsening parallel to leg pain. His doctor in another institution had prescribed him non-steroidal antiinflammatory drug with a diagnosis of lumbar disc hernia. However, his complaints were not relieved.

He reported that he was a heavy smoker by smoking 2 to 3 packets of cigarettes daily, for 30 years. His medical history was positive for type 2 diabetes mellitus, hypertension and coronary heart disease. His daily medications include aspirin $100 \mathrm{mg}$, candesartan/hydrochlorothiazide $16 / 12,5 \mathrm{mg}$, atorvastatin $20 \mathrm{mg}$, carvedilol $12,5 \mathrm{mg}$, and metformin $2 \mathrm{~g}$ (in two equal doses). His family history was irrelevant.

Physical examination revealed that he was well on appearance, conscious, cooperated and oriented. Blood pressure was $140 \mathrm{mmHg}$ systolic and $80 \mathrm{mmHg}$ diastolic. Heart rate was 84 beats per minute and respiratory rate was 16 per minute. His body temperature was $36,5^{\circ} \mathrm{C}$. Bilateral rhonchi and crackles in both hemi-thorax was noted. Other positive physical examinations include, hepatomegaly, bilateral ++ pretibial edema and bilateral 4/5 muscle strength in both lower extremities. Rest of the physical examination findings were normal.

Laboratory findings were as follows: fasting plasma glucose $180 \mathrm{mg} / \mathrm{dl}$, serum creatinine $0.64 \mathrm{mg} / \mathrm{dl}$, aspartate transaminase 68
U/L (reference range: 5-34 U/L), lactate dehydrogenase $>1500 \mathrm{U} / \mathrm{L}$ (reference range: 125-220 U/L), gamma glutamyl transferase $662 \mathrm{U} / \mathrm{L}$ (reference range: $12-64 \mathrm{U} / \mathrm{L}$ ), hemoglobin: $11.1 \mathrm{~g} / \mathrm{dL}$, mean corpuscular volume $91 \mathrm{fL}$, serum iron $19 \mathrm{ug} / \mathrm{dL}$ (reference range: 31-144 ug/dL), iron binding capacity 177, ferritin $349 \mathrm{ng} / \mathrm{dL}$ (reference range: 21$274 \mathrm{ng} / \mathrm{dL}$ ) and erythrocyte sedimentation rate $101 \mathrm{~mm} /$ hour. Vitamin B12 and folate levels in the serum and all of the serum electrolytes and biochemistry parameters were normal.

Right hilar opacity was visualized in a chest $\mathrm{x}$ ray radiograph. Therefore, a computerized tomography (CT) of thorax ordered. Thoracic CT revealed a $25 \times 35 \times 30 \mathrm{~mm}$ mass with lobulated contour in apical of basal segment of lower lobe in right lung and a metastatic mass lesion with $32 \times 45 \times 36 \mathrm{~mm}$ diameters, destructed the $3^{\text {rd }}$ right costa laterally. CT was also revealed widespread metastatic nodules in the liver. Lytic metastatic lesions were noted in T1, T5-8 and L1 vertebrae. The lesion in right lung was biopsied by interventional radiologist. The patient's medical condition worsened, respiratory failure developed, and he transferred to intensive care unit. He deceased due to multisystem failure on $7^{\text {th }}$ day of admission. After he died, pathology specimen was reported the biopsy material as adenocarcinoma of the lung.

\section{Discussion}

Adenocarcinoma is the most common type of lung cancers [2]. It has an aggressive course despite treatment and patients' survival is about 5 years. Diagnosis usually established in advanced stages. Present case was stage 4 adenocarcinoma because there were hepatic and spinal metastasis before the diagnosis confirmed by histopathologic examination.

${ }^{\star}$ Correspondence to: Gulali Aktas, Abant Izzet Baysal University Hospital, Department of Internal Medicine, Golkoy, 14280, Bolu, Turkey, Tel: +903742534656; Email: draliaktas@yahoo.com

Key words: neuropathy, cancer, adenocarcinoma, cigarette smoking

Received: February 09, 2018; Accepted: February 28, 2018; Published: March 16,2018 
Adenocarcinoma is more common in men than women [3]. Risk of lung adenocarcinoma increase by smoking; both duration of smoking habit and number of cigarettes smoked per day [4,5]. Like the literature, present patient was a 49 years old man and he was a heavy smoker for 30 years.

The rate of cancer related pain is about $71 \%$ in advanced or metastatic cancers [6]. Lung cancer is the third most common cancer that associated with pain [7]. Present case was also presented with leg pain and weakness in lower extremities.

Lung is the first, liver is the second, adrenal gland is the third and bone is the $4^{\text {th }}$ common site of metastases in lung cancer cases [8]. Although lung, bone (vertebral) and hepatic metastases were present in the patient, no adrenal metastasis were detected in CT scan.

Pain and weakness in lower extremities in adenocarcinoma may be due to chemotherapy, metabolic complications, nutritional deficits, or infiltration of spinal cord or nerves by the tumor. Vitamin B12 and folate were normal therefore nutritional deficiencies were ruled out in differential diagnosis in present case. He was not received chemotherapy since the diagnosis was confirmed after he deceased. Serum electrolytes of the patient, including serum calcium were in normal range, so, metabolic neuropathy was ruled out, too. Vertebral and spinal metastases may be responsible of weakness and pain in lower extremities in present case. However, it was misdiagnosed with lumbar disc hernia in another hospital and a delay of diagnosis encountered in the case.

\section{Conclusion}

In conclusion, weakness and pain in extremities in a subject with a history of heavy smoking should alert physicians for possible lung malignancy. A thoracic CT should be performed for establishing diagnosis.

\section{References}

1. Croft P, Wilkinson M (1965) The incidence of carcinomatous neuromyopathy in patients with various types of carcinoma. Brain 88: 427-434. [Crossref]

2. Denisenko TV, Budkevich IN, Zhivotovsky B (2018) Cell death-based treatment of lung adenocarcinoma. Cell death \& disease 9: 117. [Crossref]

3. Charloux A, Quoix E, Wolkove N, Small D, Pauli G, et al. (1997) The increasing incidence of lung adenocarcinoma: reality or artefact? A review of the epidemiology of lung adenocarcinoma. International journal of epidemiology 26: 14-23. [Crossref]

4. Lubin JH, Blot WJ (1984) Assessment of lung cancer risk factors by histologic category. $J N C I$ 73: 383-389. [Crossref]

5. Wu AH, Henderson BE, Pike MC, Yu MC (1985) Smoking and other risk factors for lung cancer in women. Journal of the National Cancer Institute 74: 747-751.

6. Goudas LC, Bloch R, Gialeli-Goudas M, Lau J, Carr DB (2005) The epidemiology of cancer pain. Cancer investigation 23: 182-190. [Crossref]

7. Van den Beuken-van Everdingen M, De Rijke J, Kessels A, Schouten H, Van Kleef M, et al. (2007) Prevalence of pain in patients with cancer: a systematic review of the past 40 years. Annals of oncology 18: 1437-1449. [Crossref]

8. Abrams HL, Spiro R, Goldstein N (1950) Metastases in carcinoma. Analysis of 1000 autopsied cases. Cancer 3: 74-85. [Crossref]

Copyright: (C2018 Kocak MZ. This is an open-access article distributed under the terms of the Creative Commons Attribution License, which permits unrestricted use, distribution, and reproduction in any medium, provided the original author and source are credited. 